\title{
A Survey of the Experience and Impact of Acute Upper Respiratory Tract Infections on People in Six Countries in the 2011/2012 Common Cold and Flu Season*
}

\author{
John David Hull ${ }^{1}$, Ian Paul Barton ${ }^{1}$, Jennifer Torgersen ${ }^{2}$, Christine Marie McNeil ${ }^{3}$ \\ ${ }^{1}$ Greater London Innovation Centre, Procter \& Gamble, Egham, UK \\ ${ }^{2}$ Ipsos Marketing, Cincinnati, USA \\ ${ }^{3}$ Mason Business Centre, Procter \& Gamble, Cincinnati, USA \\ Email: hull.jd.2@pg.com
}

Received October 30, 2013; revised November 15, 2013; accepted November 21, 2013

Copyright (c) 2013 John David Hull et al. This is an open access article distributed under the Creative Commons Attribution License, which permits unrestricted use, distribution, and reproduction in any medium, provided the original work is properly cited.

\begin{abstract}
Introduction: Acute Upper Respiratory Tract Infections (URTIs) are the most common infectious diseases of humankind. While usually mild and self-limiting, they are characterized by a series of simultaneously occurring symptoms/ signs that are sufficiently disruptive to sufferers' normal activities in which medication is frequently sought. While the literature has many examples of epidemiological studies on these infections, there are few reports on patient experience and impact. This study was designed to investigate these aspects of Common Cold/Flu across six countries. Methods: A minimum of 500 adults aged 18 and older were recruited in each of six countries (Brazil, China, Germany, India, Russia, and the US) using customary survey research sampling techniques. Single 30-minute (online) or 40-minute door-to-door quantitative questionnaires with c. 50 questions were completed with each participant by the global research firm Ipsos. Main Findings: Across countries, incidence and seasonality of infections reported to this study were consistent with published data. There appears to be a need for patient education on the causes and transmission routes of respiratory infections. Getting good quality sleep and being able to continue with daily activities as an infection resolves are significant drivers to therapy. The most common non-prescription therapies reported were multi-ingredient products in line with the simultaneously occurring multi-symptom nature of the condition(s). Conclusions: This study indicated that acute URTIs exert a significant deleterious effect on sufferers. Public health education, possibly best undertaken by Pharmacists has the potential to impact the extent of virus transmission by ensuring that people know the true cause of the infection, how it is transmitted and how best to combat this. The several simultaneously occurring symptoms encourage sufferers to seek multi-ingredient remedies to allow them to continue with normal activities as their infection resolves naturally.
\end{abstract}

Keywords: Common Cold; Upper Respiratory Tract Infections; Common Cold Survey

\section{Introduction}

The common cold, colloquially described as cough, cold and flu, but more accurately, acute Upper Respiratory Tract Infection (URTI), is the most common infectious

\footnotetext{
"Financial Interests: At the time of conducting this study and preparing this manuscript, JD Hull, IP Barton, C McNeil were full-time employees of The Procter \& Gamble Company and may have stock and/or stock options in the company.

Study Involvement: JD Hull and IP Barton were responsible for interpretation of study results and publication drafting. Ipsos were responsible for study execution and statistical analyses. C McNeil was responsible for oversight of the study design and execution. All attributed authors participated in the development and review of this manuscript.
}

disease of humans [1-3]. The literature indicates that adults can experience two to four episodes a year and children five to seven [2-3].

Acute respiratory viral infections have strong seasonal patterns, but sporadic cases or nosocomial outbreaks can occur year-round. In temperate areas, the enveloped viruses, such as influenza virus, respiratory syncytial virus (RSV), and coronavirus, are characteristically prevalent during autumn and winter periods, whereas non-enveloped viruses, such as rhinoviruses, are found most often in early spring and autumn [4].

URTI is generally a mild illness of the upper respira- 
tory tract, primarily affecting the nasopharynx and paranasal sinuses. It is so well recognised by patients that it has recently been described as more akin to a cultural concept than a clinical entity [1]. Consequently it is most often diagnosed by patients and caregivers without recourse to a physician, and the symptom complex can be relieved successfully with non-prescription products.

Rhinoviruses, which cause about $50 \%$ of colds, and coronaviruses, which cause $10 \%$ to $20 \%$, are the most important pathogens [2]. No etiological agent can be identified in approximately $30 \%$ of common cold episodes. The same pathogens have been identified as causing colds in developing countries [5] although few etiological studies have been reported. Adults with rhinovirus colds typically have prominent upper respiratory tract symptoms (i.e., sneezing, nasal discharge, nasal obstruction, sore or scratchy throat, and cough) and often have headache but little fever or other systemic complaints except malaise [6]. There is no way of identifying the virological nature of the infection from the symptoms as these are very similar across the range of caustive viruses.

A study in 2002 from the United States confirmed the magnitude of the economic cost of the common cold. It was estimated that $\$ 25$ billion is lost due to non-influenza common cold, of which $\$ 16.6$ billion is lost on-thejob productivity, $\$ 8$ billion is due to direct employee absenteeism and \$230 million is due to caregiver absenteeism [7].

The epidemiology of URTIs has been variously reported from the 1960s (see for example, [5,8-13]. These studies tracked the types and incidence of infection along with the temporal frequency of symptoms but they did not assess in any detail the impact of the illnesses on patient well-being.

To address this, we sponsored a pilot study in June 2011 (unpublished) to assess the feasibility of capturing data on the attitudes and experiences of individuals who had acute upper respiratory tract infections. Online collection of data related to people's experiences and impact of upper respiratory tract infections in the previous 12 months. Data obtained in high internet penetration countries such as US, Germany, France \& Australia mirrored national census results. The demographic composition of online samples obtained in low internet penetration countries such as Mexico, Russia, Poland, Brazil \& India were found to be non-representative. Based on these findings, and the need to revise some questions that seemed to have been asked in a leading manner, a further study was initiated in 2012 with revised questions and with data collection online in the US and Germany and via door-to-door interviews in Brazil, China, India and Russia. The intent was to survey basic epidemiology and adult attitudes, experiences and impact related to infec- tions commonly described by patients as "Cough Cold Flu”, from individuals in the 6 countries, representing a reasonable cross-section of socioeconomic status. Reported here are the results of the 2012 study.

\section{Methods}

Participants: Adults from 6 countries (Brazil, China, Germany, India, Russia and the US) were recruited to participate in the study. These countries were chosen to be representative of significant Developed and Developing economies. Eligible participants were those aged at least 18 years, not involved in marketing of consumer or pharmaceutical products, or in market research, in an advertising agency, or for a newspaper or television station. No questions regarding present health status were asked. The intent was to recruit 500 adults who met the enrolment criteria from each country, with an equal proportion of females and males. A total of 500 were recruited in Brazil, 540 in Germany, 509 in India, 541 in Russia, 500 in China and 519 in the US.

During June to August 2012, 30-minute online (Germany and US) or 40-minute door-to-door quantitative questionnaires (Brazil, China, India and Russia) were conducted in accordance with standard local market research practices in each country. Participants in Germany and the US were recruited from Ipsos' national online panels using sample targeting techniques to ensure that sample composition reflected the total population according to country census data. In the other four countries participants were recruited door-to-door using probability sampling techniques. This was used in 6 cities in Brazil (São Paulo, Rio de Janeiro, Belo Horizonte, Porto Alegre, Recife, Ribeirão Preto), 8 cities in China (Beijing, Shanghai, Guangzhou, Chengdu, Nanjing, Shijiazhuang, Zhanjiang, Liuzhou), 8 cities and 4 villages in India (Delhi, Mumbai, Chennai, Kolkata, Asansol, Amravati, Gorakhupur, Guntur, Amravati villages, Gorakhpur villages, Guntur villages, Asansol villages) and 6 cities in Russia (Moscow, St Petersburg, Yekaterinburg, Nizhny Novgorod, Voronezh, Tver).

Consent was obtained from on-line panellists when they signed up to the panel and door-to-door interviewees were asked to consent to the interview "on-site". All panellists were assured of confidentiality and preservation of anonymity.

Measurements: The quantitative questionnaire comprised approximately 50 questions covering three main areas: inclusion/exclusion criteria, demographics and experiences \& habits associated with upper respiratory tract infections. Closed questions were asked with the majority being asked in a randomised order to avoid bias. The data presented here exclude a small sub-set of all questions asked that were related to commercial products rather than the illness. It is judged unlikely that any of 
the product-related questions affected responses to those reported here

Quality Checks: Ipsos performed multiple quality checks throughout the process, including 1) the questionnaire phase to ensure the language was consumerfriendly and that the logic of the questionnaire was correct, 2) the online survey link to ensure the logic was working correctly and there were no technical errors, and 3) that the data tables were thoroughly checked for accuracy of survey logic, as well as applying category knowledge checks.

Statistical Analysis: Data from all participants who completed the questionnaire were summarised using descriptive statistics (e.g. N, Percentage, Mean and Standard Deviation) by country. Between-country statistical testing was undertaken to aid further interpretation of the data. All statistical tests were performed at the 2-tailed $5 \%$ level of significance. No adjustment for multiple testing was used.

\section{Results}

In total some 50 questions were asked at each interview (on-line or in person). In the original questions the colloquial term, "Cough Cold Flu” was used to elicit information on upper respiratory tract infections. This colloquialism is widely understood by the general population but responses based upon it raised difficulties of interpretation. As cough is a symptom associated with several acute and chronic conditions in addition to Common Cold or Flu, it is possible that there has been some overreporting in the data presented below. This is judged unlikely to affect the overall findings and conclusions.

Basic demographic data are presented in Table 1. Of the 3109 respondents that formed the study population,
$50 \%$ were female and the mean age of the population was 42 years (range of means: 37 years in India; 48 years in Germany). Overall, 86\% (percentage across the countries) of participants recorded experiencing a Cold/Flu in the past 12 months. There were differences between countries with $91 \%$ and $99 \%$ of the Chinese and Indian populations respectively reporting symptoms of a Cold or Flu compared with 75\% (US) and 83\% - 85\% in Germany, Brazil and Russia.

The reported incidence of allergy symptoms was greater in the US (53\%), Brazil (22\%) and Germany (19\%). The lowest incidence was reported in China (5\%), Russia (9\%) and India (11\%). This is consistent with reports of differences in allergy incidence across national boundaries by the World Allergy Organization [14].

The data in Table 2 indicate that overall 77\% of respondents reported illness incidences of 1 - 4 per year with a mean of 2 (SD 1.3) in line with published rates [2], with the highest reporting rates ( 1 - 4 illnesses per year) in China and India (86\% each). Consistent with this, reporting of rarely or never experiencing a respiratory illness was lowest in China (8\%) and India (2\%). Countries reporting the lowest experiences of 1 - 4 illnesses annually were the US, Germany \& Russia with similar averages of 1.7 - 1.9 .

Table 3 shows that the mean duration of illness was reported to be 6 (SD 3.3) days. Published reports suggest that the mean duration of Common Cold is between 7 and 10 days [2]. The incidence data in Table 3 show that overall, 74\% respondents in this study reported infections of between 1 day and 1 week and just 11\% reported illness lasting up to 2 weeks. The highest reporting rates of illness lasting between 1 day and 1 week were in Brazil (79\%), China (86\%) and India (92\%). Respondents in

Table 1. Demographics.

\begin{tabular}{|c|c|c|c|c|c|c|c|}
\hline & Total & US a & Germany b & Brazil c & China d & Russia e & India f \\
\hline BASE: total respondents & 3109 & 519 & 540 & 500 & 500 & 541 & 509 \\
\hline \multirow[t]{2}{*}{ Average age } & 42.25 & 46.74 & 48.23 & 37.84 & 39.61 & 43.28 & 37.14 \\
\hline & & cdef & cdef & abde & abcef & abcdf & abde \\
\hline SD & 15.34 & 16.23 & 16.12 & 12.91 & 12.49 & 15.86 & 14.14 \\
\hline Male & $50 \%$ & $48 \%$ & $51 \%$ & $55 \%$ & $50 \%$ & $46 \%$ & $50 \%$ \\
\hline Female & $50 \%$ & $52 \%$ & $49 \%$ & $45 \%$ & $50 \%$ & $54 \%$ & $50 \%$ \\
\hline \multicolumn{8}{|c|}{ Symptoms experienced in previous 12-month } \\
\hline Allergies & $20 \%$ & $53 \%$ bcdef & $19 \%$ adef & $22 \%$ adef & $5 \%$ abcef & $9 \%$ abcd & $11 \%$ abcd \\
\hline
\end{tabular}

Letters in the table signify that the data within a particular country's cell was statistically significant at the 2-tailed 5\% level of significance (e.g. if the US had bcdef it would infer that the data was statistically significantly different to the other 5 countries). 
Table 2. Incidence of respiratory illness.

\begin{tabular}{|c|c|c|c|c|c|c|c|}
\hline & Total & US a & Germany b & Brazil c & China d & Russia e & India $f$ \\
\hline BASE: total respondents & 3109 & 519 & 540 & 500 & 500 & 541 & 509 \\
\hline \multicolumn{8}{|l|}{$\begin{array}{l}\text { Average number of times a year } \\
\text { experience CCF symptoms }\end{array}$} \\
\hline 1 - 2 per year $[1.5]^{*}$ & $54 \%$ & $45 \%$ & $50 \%$ & $56 \%$ & $60 \%$ & $63 \%$ & $47 \%$ \\
\hline 3 - 4 per year $[3.5]^{*}$ & $23 \%$ & $20 \%$ & $21 \%$ & $16 \%$ & $26 \%$ & $20 \%$ & $39 \%$ \\
\hline 5 or more per year $[5]^{*}$ & $7 \%$ & $5 \%$ & $5 \%$ & $12 \%$ & $5 \%$ & $4 \%$ & $13 \%$ \\
\hline I hardly ever catch a CCF/never $[0.25]^{*}$ & $15 \%$ & $31 \%$ & $25 \%$ & $16 \%$ & $8 \%$ & $14 \%$ & $2 \%$ \\
\hline \multirow[t]{2}{*}{ Mean } & 2.05 & 1.72 & 1.79 & 2.08 & 2.11 & 1.89 & 2.73 \\
\hline & & cdef & cdf & abef & abef & acdf & abcde \\
\hline SD & 1.34 & 1.35 & 1.32 & 1.43 & 1.21 & 1.16 & 1.29 \\
\hline
\end{tabular}

*Values assigned to individual responses and used to create Mean and SD. Letters in the table signify that the data within a particular country's cell was statistically significant at the 2-tailed 5\% level of significance (e.g. if the US had bcdef it would infer that the data was statistically significantly different to the other 5 countries).

Table 3. Duration of respiratory illness.

\begin{tabular}{|c|c|c|c|c|c|c|c|}
\hline & Total & US a & Germany b & Brazil c & China d & Russia e & India $f$ \\
\hline BASE: total respondents & 3109 & 519 & 540 & 500 & 500 & 541 & 509 \\
\hline \multicolumn{8}{|l|}{$\begin{array}{l}\text { Average number of days ccf } \\
\text { symptoms lasted for LAST CCF }\end{array}$} \\
\hline $1-3$ days $[2]^{*}$ & $25 \%$ & $26 \%$ & $14 \%$ & $29 \%$ & $30 \%$ & $12 \%$ & $42 \%$ \\
\hline 4 - 6 days $[5]^{*}$ & $29 \%$ & $28 \%$ & $30 \%$ & $24 \%$ & $34 \%$ & $24 \%$ & $37 \%$ \\
\hline 1 week $[7]^{*}$ & $20 \%$ & $14 \%$ & $19 \%$ & $26 \%$ & $22 \%$ & $28 \%$ & $13 \%$ \\
\hline More than a week, but less than 2 weeks [10] ${ }^{*}$ & $11 \%$ & $10 \%$ & $22 \%$ & $9 \%$ & $4 \%$ & $15 \%$ & $5 \%$ \\
\hline $2+$ weeks $[14]^{*}$ & $6 \%$ & $7 \%$ & $9 \%$ & $6 \%$ & $1 \%$ & $7 \%$ & $3 \%$ \\
\hline I can't remember/not experienced a CCF $[0.25]^{*}$ & $9 \%$ & $15 \%$ & $6 \%$ & $6 \%$ & $8 \%$ & $14 \%$ & $1 \%$ \\
\hline \multirow[t]{2}{*}{ Mean } & 5.77 & 5.77 & 6.99 & 5.7 & 4.86 & 6.84 & 4.46 \\
\hline & & bdef & acdf & bdef & abcef & acdf & abcde \\
\hline SD & 3.27 & 3.54 & 3.45 & 3.33 & 2.47 & 3.2 & 2.7 \\
\hline
\end{tabular}

*Values assigned to individual responses and used to create Mean and SD. Letters in the table signify that the data within a particular country's cell was statistically significant at the 2-tailed 5\% level of significance (e.g. if the US had bcdef it would infer that the data was statistically significantly different to the other 5 countries).

Germany reported the greatest frequency of illnesses lasting more than 1 week at $31 \%$.

Consistent with expectations [2], the highest frequency of respiratory illness (66\%) was reported to have occurred during winter with rates in autumn and spring being similar at 35\% and 31\% respectively (Table 4). Respondents in Russia reported the fewest illnesses during summer (9\%) and those in India reported the highest (34\%) (Figure 1).

Subjects were asked to report where/how they judged it most likely that they caught their infection (Table 5).
They were asked to choose from: public places, cold indoor environments (chill), personally predisposed to infection, from a work colleague, from spouse/partner. Overall, public places (39\%), "catching a chill sitting in a room with freezing temperatures” (34\%) and predisposition (30\%) were the most frequently reported. Becoming infected by colleagues or spouse/partner was reported least frequently (22\% and 23\% respectively) (Data not shown). Respondents in Russia reported public places as the most likely source of infection (57\%) and those in India judged their personal predisposition to infection as 
Table 4. Seasonality of respiratory illness.

\begin{tabular}{|c|c|c|c|c|c|c|c|}
\hline & Total & US a & Germany b & Brazil c & China d & Russia e & India $f$ \\
\hline BASE: total respondents & 3109 & 519 & 540 & 500 & 500 & 541 & 509 \\
\hline \multirow[t]{2}{*}{ Autumn } & $35 \%$ & $31 \%$ & $40 \%$ & $15 \%$ & $28 \%$ & $34 \%$ & $64 \%$ \\
\hline & & bcf & acdef & abdef & bcef & bcdf & abcde \\
\hline \multirow[t]{2}{*}{ Winter } & $66 \%$ & $62 \%$ & $59 \%$ & $70 \%$ & $65 \%$ & $67 \%$ & $70 \%$ \\
\hline & & $\mathrm{cf}$ & cef & $\mathrm{ab}$ & & $\mathrm{b}$ & $\mathrm{ab}$ \\
\hline \multirow[t]{2}{*}{ Spring } & $31 \%$ & $38 \%$ & $40 \%$ & $10 \%$ & $49 \%$ & $37 \%$ & $11 \%$ \\
\hline & & cdf & cdf & abde & abcef & cdf & bde \\
\hline \multirow[t]{2}{*}{ Summer } & $22 \%$ & $18 \%$ & $19 \%$ & $27 \%$ & $26 \%$ & $9 \%$ & $34 \%$ \\
\hline & & cdef & cdef & abef & abef & abcdf & abcde \\
\hline
\end{tabular}

Letters in the table signify that the data within a particular country's cell was statistically significant at the 2-tailed 5\% level of significance (e.g. if the US had bcdef it would infer that the data was statistically significantly different to the other 5 countries).

Table 5. Likely source of infection.

\begin{tabular}{|c|c|c|c|c|c|c|c|}
\hline & Total & US a & Germany b & Brazil c & China d & Russia e & India $f$ \\
\hline BASE: suffered cough, cold, flu past 12 months & 2672 & 387 & 447 & 417 & 455 & 460 & 506 \\
\hline \multirow[t]{2}{*}{ Total environmental } & $61 \%$ & $51 \%$ & $70 \%$ & $64 \%$ & $66 \%$ & $68 \%$ & $45 \%$ \\
\hline & & bcde & af & af & af & af & bcde \\
\hline \multirow[t]{2}{*}{ Passed on to me by someone else } & $54 \%$ & $73 \%$ & $76 \%$ & $28 \%$ & $56 \%$ & $48 \%$ & $45 \%$ \\
\hline & & cdef & cdef & abdef & abcef & abcd & abcd \\
\hline \multirow[t]{2}{*}{ From public places (e.g. bus/subway/train/airplane) } & $39 \%$ & $48 \%$ & $52 \%$ & $37 \%$ & $20 \%$ & $57 \%$ & $25 \%$ \\
\hline & & cdef & cdf & abdef & abce & acdf & abce \\
\hline \multirow[t]{2}{*}{ Not taking care of myself } & $37 \%$ & $53 \%$ & $54 \%$ & $20 \%$ & $41 \%$ & $25 \%$ & $30 \%$ \\
\hline & & cdef & cdef & abdf & abcef & abd & abcd \\
\hline I caught a chill sitting in a room with freezing temperatures & $34 \%$ & $11 \%$ & $41 \%$ & $44 \%$ & $55 \%$ & $28 \%$ & $22 \%$ \\
\hline \multirow[t]{2}{*}{ I have a tendency to catch cough/cold/flu } & $30 \%$ & $26 \%$ & $37 \%$ & $23 \%$ & $27 \%$ & $27 \%$ & $39 \%$ \\
\hline & & bf & acde & bf & bf & bf & acde \\
\hline \multirow[t]{2}{*}{ I was not getting enough sleep } & $23 \%$ & $36 \%$ & $33 \%$ & $5 \%$ & $35 \%$ & $7 \%$ & $23 \%$ \\
\hline & & cef & cef & abdf & cef & abdf & abcde \\
\hline \multirow[t]{2}{*}{ I was not taking vitamins or preventative medications } & $13 \%$ & $16 \%$ & $26 \%$ & $9 \%$ & $4 \%$ & $17 \%$ & $6 \%$ \\
\hline & & bcdf & acdef & abdef & abce & bcdf & abce \\
\hline
\end{tabular}

Letters in the table signify that the data within a particular country's cell was statistically significant at the 2-tailed 5\% level of significance (e.g. if the US had bcdef it would infer that the data was statistically significantly different to the other 5 countries).

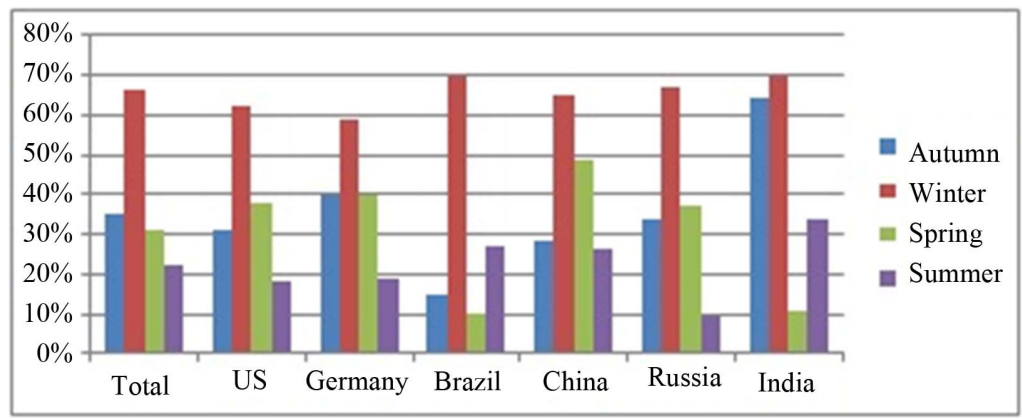

Figure 1. Seasonality of respiratory illness. 
most likely (39\%). Those in Brazil and China reported "catching a chill sitting in a room with freezing temperatures" as the most likely source of infection (44\% and $55 \%$ respectively) whereas those in the US and India judged this least likely (11\% and 22\% respectively).

There is little discussion in the scientific literature of the impact of URTIs on the attitude of spouses or partners to respiratory illness in the family. Therefore we asked a series of questions which included how sympathetic respondents were when their spouse or partner was experiencing a URTI. One of these requested subjects to judge how sympathetic they were to a spouse or partner experiencing a respiratory illness. A four point Likert scale was used-very sympathetic (I cannot do enough to make them feel better), somewhat sympathetic (I understand how unwell they must be feeling), somewhat unsympathetic (I feel they exaggerate their symptoms), very unsympathetic (I get frustrated at their ill health). Overall respondents reported substantially greater tendency to be sympathetic than unsympathetic (89\% "very" or "somewhat" sympathetic and $11 \%$ "somewhat" or "very" unsympathetic). This pattern was consistent across respondents from the six countries (data not shown).

We also sought to understand how people with a URTI inform themselves on treatment options (Table 6). Overall most respondents reported relying mostly on a physician or pharmacist to provide advice and information on Cold and Flu (73\%). The US was notable for the lowest score $(41 \%)$ and India for the highest $(95 \%)$ on this parameter. Reliance on past experience (68\%), parents and family (55\%) and pack details read at the time of purchase (55\%) were the next most commonly reported sources. Overall the internet and general health magazines were the least reported sources.

Subjects were asked to record which of the following represented their most frequently taken actions when experiencing a Common Cold: take OTC remedy, get rest/sleep, increase fluid intake, take warm drinks, take herbal teas. Taking OTC remedies and getting rest/sleep were the most frequently recorded at $40 \%$ and $39 \%$ respectively (Figure 2). Respondents in China reported getting rest/sleep as the most often taken action at 58\% while those in Brazil recorded this as least often. Russian respondents recorded most use of OTC remedies and herbal teas at $61 \%$ and $41 \%$ respectively. Those in India used tea/coffee most often (59\%). Respondents from the US and China reported these options least frequently at $11 \%$ and $7 \%$ respectively for tea/coffee and $9 \%$ and $2 \%$ respectively for herbal teas.

When asked the reasons for taking OTC remedies, "To get a good night's sleep" (33\%) and "To carry on with my daily routine" (32\%) were the most frequently recorded (Table 7, Figure 3). Sleep was selected by most respondents in the US (40\%), Germany (39\%) and China
(39\%) while in Russian respondents were least likely to select this option (14\%). "To carry on with my daily routine" was more important to respondents in Brazil (42\%) and India (44\%) than the other countries while for respondents in Germany, "To be liberated from my symptoms" was of greater importance (43\%) than reported by other nationals. Indian respondents reported "So I do not spread my cough/cold/flu to others" as more important (35\%) than other respondents.

Overall respondents reported using multi-symptom products most often in the past 12 months at $66 \%$ with cough medicine as second most frequently used at $58 \%$ (Table 8, Figure 4). Respondents in Brazil (76\%), China (88\%) and India (74\%) reported use of multi-symptom remedies most often with those in Germany reporting their use least often (29\%). The use of cough medicines was reported most often in China (65\%) and India (79\%) and least often in Germany (44\%). Nasal decongestants were reported most commonly in Russia (55\%) and cough/throat drops most often in Germany (72\%).

The impact of both personal illness and the impact of the illness of others on care-givers were assessed (Table 9, Figure 5). Overall 2.5 (SD 2.21) days were reported lost over the past 12 months because of personal respiratory illness, 1.8 (SD 2.13) due to ill children and 1.6 (SD 2.09) due to illness affecting the whole family. Respondents in Russia reported the most days lost to illness and Brazil the least by all three measures-personal illness (Russia 4.0, Brazil 1.4), children's illness (Russia 4.1, Brazil 0.9) and family illness (Russia 3.7, Brazil 0.3).

The impact of URTIs on sleep is shown in Table $\mathbf{1 0}$ and Figure 6. Overall respondents reported waking up twice per night while suffering from a respiratory illness (Mean 1.9, SD 1.32). Respondents in Germany reported the highest number (Mean 2.4, SD 1.32) and China the lowest (Mean 1.4, SD 1.19).

Three questions were asked to better understand important aspects of the impact of respiratory illness on, 1) associated health concerns, 2) mood and 3) likelihood to perform some normal activities. The data in Table 11 indicates that overall respondents were most concerned about passing an infection to others (18\%) and being able to work normally (18\%). Concern that symptoms could develop into a more serious illness (16\%), concerns about the ability to sleep (12\%) and being able to perform household chores (10\%) were less important. Respondents in China and the US were most concerned about passing on an illness (32\% and 20\% respectively) while those in India and Brazil were least concerned (11\% and $14 \%$ respectively). Concern that an illness may develop into something worse was most reported by respondents from the US (23\%), Russia (23\%) and Germany $(21 \%)$ and least concerning to those from India (5\%). Only respondents from India reported inability to 
Table 6. Sources of information on therapy for respiratory illness-agreement statements.

\begin{tabular}{|c|c|c|c|c|c|c|c|}
\hline & Total & $\begin{array}{c}\text { US } \\
\mathbf{a}\end{array}$ & $\begin{array}{l}\text { Germany } \\
\text { b }\end{array}$ & $\begin{array}{l}\text { Brazil } \\
\text { c }\end{array}$ & $\begin{array}{c}\text { China } \\
\text { d }\end{array}$ & $\begin{array}{c}\text { Russia } \\
\text { e }\end{array}$ & $\underset{f}{\text { India }}$ \\
\hline \multicolumn{8}{|c|}{ Percentage of respondents who strongly agreed or agreed } \\
\hline BASE: total respondents & 3109 & 519 & 540 & 500 & 500 & 541 & 509 \\
\hline $\begin{array}{l}\text { I rely mostly on my doctor or pharmacist to give } \\
\text { me information about cough/cold/flu treatments }\end{array}$ & $73 \%$ & $\begin{array}{l}41 \% \\
\text { bcdef }\end{array}$ & $\begin{array}{l}73 \% \\
\text { acf }\end{array}$ & $\begin{array}{l}87 \% \\
\text { abdef }\end{array}$ & $\begin{array}{l}73 \% \\
\text { acf }\end{array}$ & $\begin{array}{c}69 \% \\
\text { acf }\end{array}$ & $\begin{array}{l}95 \% \\
\text { abcde }\end{array}$ \\
\hline $\begin{array}{l}\text { I rely mostly on making my own choices by reading the } \\
\text { labels on cough/cold/flu packages at the store shelf }\end{array}$ & $55 \%$ & $\begin{array}{l}75 \% \\
\text { bcdef }\end{array}$ & $\begin{array}{c}53 \% \\
\text { acf }\end{array}$ & $\begin{array}{c}61 \% \\
\text { abdef }\end{array}$ & $\begin{array}{c}54 \% \\
\text { acf }\end{array}$ & $\begin{array}{c}50 \% \\
\text { acf }\end{array}$ & $\begin{array}{c}40 \% \\
\text { abcde }\end{array}$ \\
\hline $\begin{array}{l}\text { I rely on cough/cold/flu treatments that my mom } \\
\text { or family have used in the past }\end{array}$ & $55 \%$ & $\begin{array}{l}37 \% \\
\text { bdef }\end{array}$ & $\begin{array}{l}50 \% \\
\text { acdef }\end{array}$ & $\begin{array}{l}71 \% \\
\text { bde }\end{array}$ & $\begin{array}{l}44 \% \\
\text { abcef }\end{array}$ & $\begin{array}{l}60 \% \\
\text { abcdf }\end{array}$ & $\begin{array}{l}69 \% \\
\text { abde }\end{array}$ \\
\hline $\begin{array}{l}\text { I purposely seek out information on maintaining } \\
\text { and improving health and wellness }\end{array}$ & $49 \%$ & $\begin{array}{l}48 \% \\
\text { ce }\end{array}$ & $\begin{array}{l}48 \% \\
\text { ce }\end{array}$ & $\begin{array}{c}62 \% \\
\text { abdef }\end{array}$ & $\begin{array}{l}52 \% \\
\text { ce }\end{array}$ & $\begin{array}{l}30 \% \\
\text { abcdf }\end{array}$ & $\begin{array}{l}52 \% \\
\text { ce }\end{array}$ \\
\hline $\begin{array}{l}\text { Having a cough, cold or the flu } \\
\text { severely affects my family }\end{array}$ & $47 \%$ & $\begin{array}{l}38 \% \\
\text { bcdf }\end{array}$ & $\begin{array}{l}30 \% \\
\text { acdf }\end{array}$ & $\begin{array}{l}57 \% \\
\text { abef }\end{array}$ & $\begin{array}{l}58 \% \\
\text { abef }\end{array}$ & $\begin{array}{l}35 \% \\
\text { cdf }\end{array}$ & $\begin{array}{l}67 \% \\
\text { abcde }\end{array}$ \\
\hline $\begin{array}{l}\text { I frequently read health, wellness or fitness } \\
\text { sections/articles in magazines and newspapers }\end{array}$ & $36 \%$ & $\begin{array}{l}37 \% \\
\text { bef }\end{array}$ & $\begin{array}{l}43 \% \\
\text { aef }\end{array}$ & $\begin{array}{l}39 \% \\
\text { ef }\end{array}$ & $\begin{array}{c}43 \% \\
\text { ef }\end{array}$ & $\begin{array}{l}31 \% \\
\text { abcdf }\end{array}$ & $\begin{array}{l}22 \% \\
\text { abcde }\end{array}$ \\
\hline $\begin{array}{l}\text { I depend on my friends and neighbors to advise } \\
\text { me when it comes to cough/cold/flu treatments }\end{array}$ & $32 \%$ & $\begin{array}{l}13 \% \\
\text { bcdef }\end{array}$ & $\begin{array}{l}21 \% \\
\text { adef }\end{array}$ & $\begin{array}{l}23 \% \\
\text { adef }\end{array}$ & $\begin{array}{l}54 \% \\
\text { abcef }\end{array}$ & $\begin{array}{l}41 \% \\
\text { abcd }\end{array}$ & $\begin{array}{l}39 \% \\
\text { abcd }\end{array}$ \\
\hline $\begin{array}{l}\text { I frequently search on the internet for } \\
\text { specific health conditions }\end{array}$ & $29 \%$ & $\begin{array}{l}42 \% \\
\text { cdef }\end{array}$ & $\begin{array}{l}42 \% \\
\text { cdef }\end{array}$ & $\begin{array}{l}32 \% \\
\text { abef }\end{array}$ & $\begin{array}{c}30 \% \\
\text { abf }\end{array}$ & $\begin{array}{l}26 \% \\
\text { abcf }\end{array}$ & $\begin{array}{l}3 \% \\
\text { abcde }\end{array}$ \\
\hline $\begin{array}{l}\text { I frequently look on the internet for general ways I } \\
\text { can maintain or improve health \& wellness }\end{array}$ & $28 \%$ & $\begin{array}{l}41 \% \\
\text { cdef }\end{array}$ & $\begin{array}{l}41 \% \\
\text { cdef }\end{array}$ & $\begin{array}{l}29 \% \\
\text { abef }\end{array}$ & $\begin{array}{l}29 \% \\
\text { abef }\end{array}$ & $\begin{array}{l}22 \% \\
\text { abcdf }\end{array}$ & $\begin{array}{l}4 \% \\
\text { abcde }\end{array}$ \\
\hline $\begin{array}{l}\text { I frequently read or subscribe to health, } \\
\text { wellness or fitness specific magazines }\end{array}$ & $25 \%$ & $\begin{array}{l}23 \% \\
\text { cde }\end{array}$ & $\begin{array}{l}23 \% \\
\text { cde }\end{array}$ & $\begin{array}{l}29 \% \\
\text { abde }\end{array}$ & $\begin{array}{l}36 \% \\
\text { abcef }\end{array}$ & $\begin{array}{c}18 \% \\
\text { abcdf }\end{array}$ & $\begin{array}{c}25 \% \\
\text { de }\end{array}$ \\
\hline
\end{tabular}

For each statement, respondents were asked to answer one of the following "Strongly agree”, “Agree”, "Neither agree nor disagree”, "Disagree” or "Strongly agree”. Letters in the table signify that the data within a particular country’s cell was statistically significant at the 2-tailed 5\% level of significance (e.g. if the US had bcdef it would infer that the data was statistically significantly different to the other 5 countries).

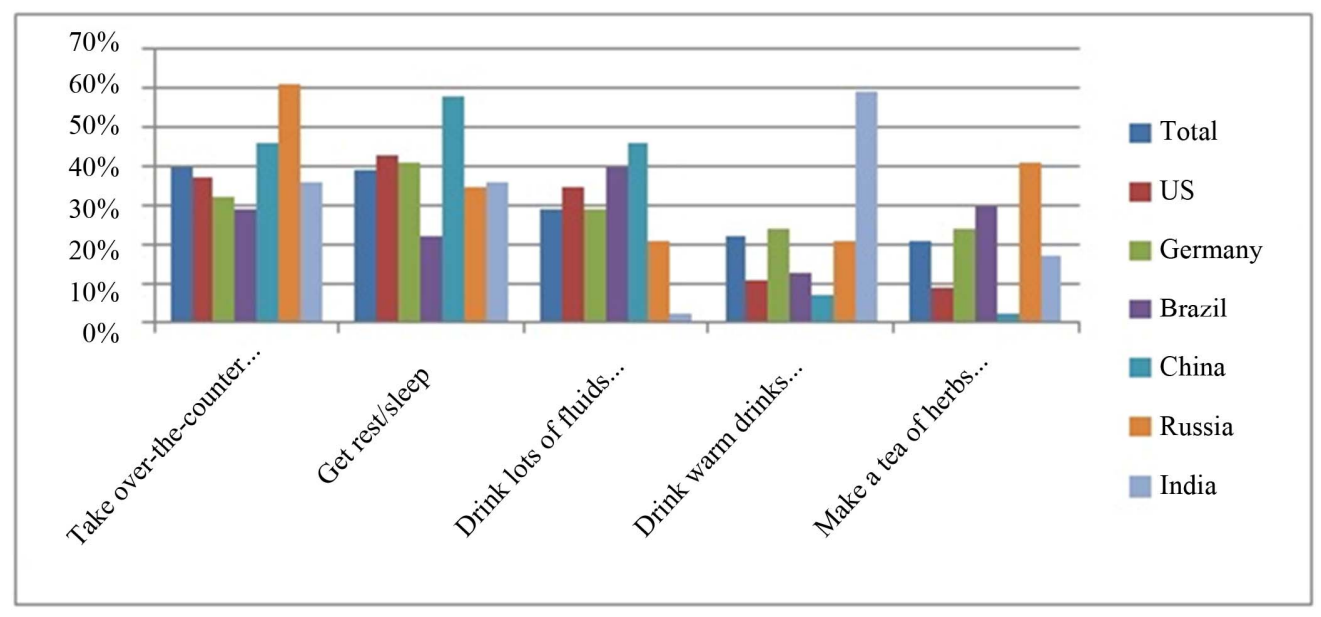

Figure 2. Top 5 actions taken when experiencing respiratory illness.

perform household chores as concerning (22\%) with the least concern on this aspect reported in the US (3\%) and Germany (4\%).

Several aspects of mood were assessed and overall respondents scored feeling "down/unhappy/tired" (24\%) and "annoyed and irritable" (23\%) were reported most frequently (Table 12). Respondents from Germany were most impacted by feeling "down/unhappy/tired” (38\%) and those from Brazil reported this least often (7\%). Brazilian respondents were most impacted by feeling "annoyed and irritable" (34\%). Respondents from China (29\%) and India (21\%) reported feeling embarrassed by their illness considerably more than other countries (US $1 \%$, Germany $2 \%$, Brazil, 3\%, Russia $9 \%$ ). 
Table 7. Top 5 reasons to use OTC remedies.

\begin{tabular}{ccccccccc}
\hline & Total & US a & Germany b & Brazil c & China d & Russia e & India f \\
\hline BASE: total respondents & 3109 & 519 & 540 & 500 & 500 & 541 & 509 \\
To get a good night sleep & $33 \%$ & $40 \%$ cef & $39 \%$ cef & $32 \%$ abde & $39 \%$ cef & $14 \%$ abcdf & $32 \%$ abde \\
To carry on with my daily routine & $32 \%$ & $33 \%$ bcef & $17 \%$ acdef & $42 \%$ abde & $31 \%$ bcef & $25 \%$ abcdf & $44 \%$ abde \\
To be liberated from symptoms & $23 \%$ & $30 \%$ bcdef & $43 \%$ acdef & $19 \%$ abf & $17 \%$ abf & $19 \%$ abf & $11 \%$ abcde \\
To heal my body & $20 \%$ & $20 \%$ bcdef & $36 \%$ acdef & $12 \%$ abe & $12 \%$ abe & $27 \%$ abcdf & $14 \%$ abe \\
So I do not spread my cough/cold/flu to others & $20 \%$ & $18 \% \mathrm{f}$ & $14 \%$ cef & $20 \%$ bf & $17 \%$ f & $19 \%$ bf & $35 \%$ abcde \\
\hline
\end{tabular}

Letters in the table signify that the data within a particular country's cell was statistically significant at the 2-tailed 5\% level of significance (e.g. if the US had bcdef it would infer that the data was statistically significantly different to the other 5 countries). Respondents were asked to check "all that apply" for these options

Table 8. Types of OTC products used to treat URTIs in past 12 months.

\begin{tabular}{|c|c|c|c|c|c|c|c|}
\hline & Total & US a & Germany b & Brazil c & China d & Russia e & India f \\
\hline BASE: suffered cough, cold or flu past 12 months & 2672 & 387 & 447 & 417 & 455 & 460 & 506 \\
\hline Multi symptom cold and flu medicine & $66 \%$ & $56 \%$ bcdef & $29 \%$ acdef & $76 \%$ abd & $88 \%$ abcef & $70 \%$ abd & $74 \%$ abd \\
\hline Cough medicine & $58 \%$ & $50 \%$ def & $44 \%$ def & $45 \%$ def & $65 \%$ abcf & $60 \%$ abcf & $79 \%$ abcde \\
\hline Nasal congestion medicine & $38 \%$ & $44 \%$ cde & $41 \%$ cde & $26 \%$ abef & $25 \%$ abef & $55 \%$ abcdf & $38 \%$ cde \\
\hline Cough/throat drops & $35 \%$ & $55 \%$ bcdef & $72 \%$ acdef & $11 \%$ abdef & $18 \%$ abce & $39 \%$ abcdf & $20 \%$ abce \\
\hline Sore throat medicine & $34 \%$ & $22 \%$ bdef & $42 \%$ acf & $21 \%$ bdef & $38 \%$ ас & $41 \%$ ac & $35 \%$ abc \\
\hline Medicated throat lozenges & $21 \%$ & $27 \%$ bcdef & $41 \%$ acdef & $16 \%$ abf & $15 \%$ abe & $20 \%$ abdf & $11 \%$ abce \\
\hline
\end{tabular}

Letters in the table signify that the data within a particular country's cell was statistically significant at the 2-tailed 5\% level of significance (e.g. if the US had bcdef it would infer that the data was statistically significantly different to the other 5 countries).

Table 9. Time lost to respiratory illness.

\begin{tabular}{|c|c|c|c|c|c|c|c|}
\hline & Total & US a & Germany b & Brazil c & China d & Russia e & India $f$ \\
\hline BASE: total respondents & 3109 & 519 & 540 & 500 & 500 & 541 & 509 \\
\hline \multicolumn{8}{|l|}{ Days stay at home because sick ${ }^{*}$} \\
\hline \multirow[t]{2}{*}{ Mean } & 2.45 & 1.55 & 3.2 & 1.36 & 1.89 & 4 & 2.3 \\
\hline & & bdef & acdef & bdef & abcef & abcdf & abcde \\
\hline SD & 2.21 & 1.90 & 2.39 & 1.83 & 1.90 & 2.10 & 1.59 \\
\hline \multicolumn{8}{|c|}{ Days stay at home because children sick } \\
\hline \multirow[t]{2}{*}{ Mean } & 1.82 & 1.04 & 1.19 & 0.87 & 1.76 & 4.11 & 2.22 \\
\hline & & def & def & def & abcef & abcdf & abcde \\
\hline SD & 2.13 & 1.58 & 1.97 & 1.69 & 1.96 & 2.56 & 1.37 \\
\hline \multicolumn{8}{|c|}{ Days stay at home because whole family sick ${ }^{*}$} \\
\hline \multirow[t]{2}{*}{ Mean } & 1.64 & 0.65 & 1.06 & 0.33 & 1.83 & 3.74 & 2.22 \\
\hline & & bcdef & acdef & abdef & abcef & abcdf & abcde \\
\hline SD & 2.09 & 1.33 & 1.97 & 1.03 & 1.88 & 2.59 & 1.62 \\
\hline
\end{tabular}

*Mean and SD calculated from following values per category: $0=0$ days, $1=1$ day, $2=2$ days, $3=3$ days, $4=4$ days, $5=5$ days, $6=$ More than 5 days, Letters in the table signify that the data within a particular country's cell was statistically significant at the 2-tailed 5\% level of significance (e.g. if the US had bcdef it would infer that the data was statistically significantly different to the other 5 countries). 


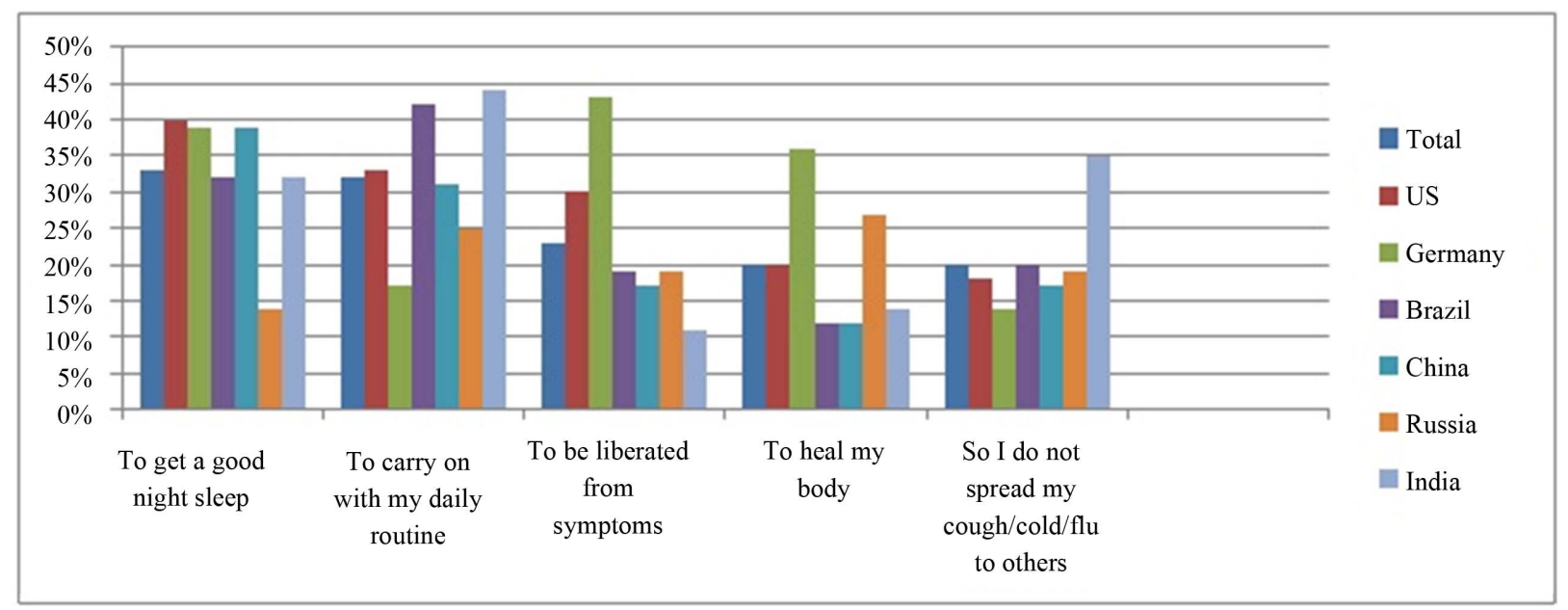

Figure 3. Top 5 reasons to use OTC remedies.

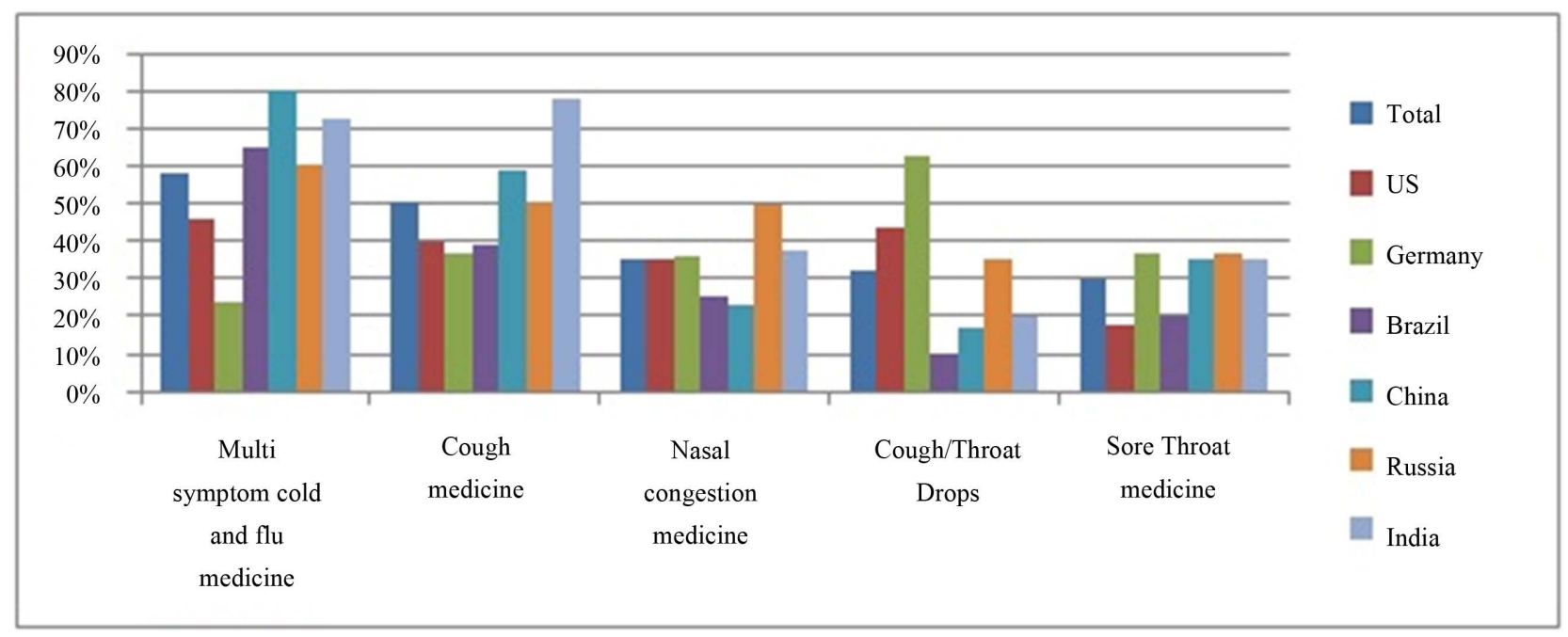

Figure 4. Top 5 products used to treat respiratory illness in previous 12 months.

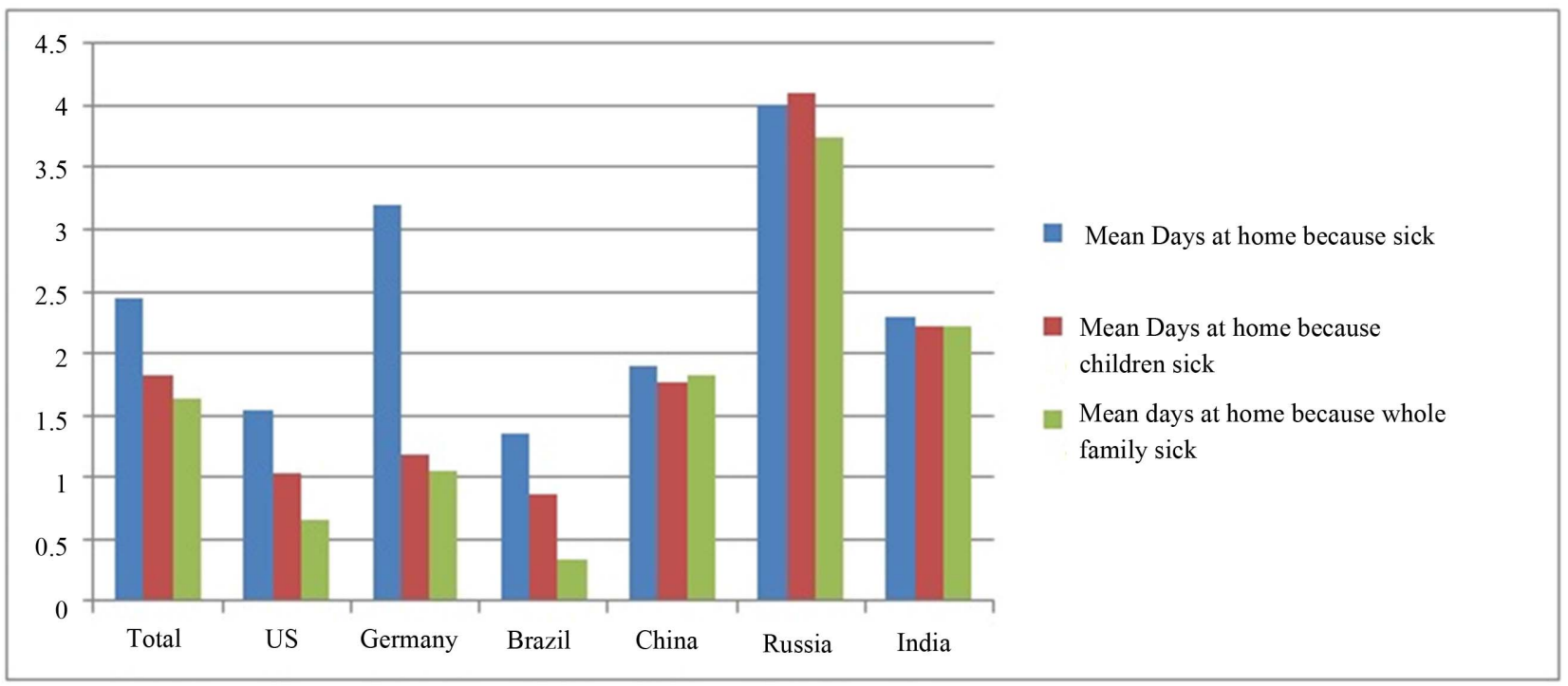

Figure 5. Time lost to respiratory illness. 
Table 10. Sleep disturbance-number of times a night wake up due to CCF symptoms.

\begin{tabular}{|c|c|c|c|c|c|c|c|}
\hline & Total & US a & Germany b & Brazil c & China d & Russia e & India $f$ \\
\hline BASE: total respondents & 3109 & 519 & 540 & 500 & 500 & 541 & 509 \\
\hline 0 & $17 \%$ & $21 \%$ & $9 \%$ & $18 \%$ & $27 \%$ & $19 \%$ & $6 \%$ \\
\hline 1 & $22 \%$ & $18 \%$ & $16 \%$ & $17 \%$ & $25 \%$ & $21 \%$ & $36 \%$ \\
\hline 2 & $30 \%$ & $29 \%$ & $29 \%$ & $27 \%$ & $32 \%$ & $26 \%$ & $39 \%$ \\
\hline 3 & $13 \%$ & $11 \%$ & $14 \%$ & $15 \%$ & $8 \%$ & $15 \%$ & $12 \%$ \\
\hline More than 3 & $18 \%$ & $21 \%$ & $31 \%$ & $24 \%$ & $8 \%$ & $19 \%$ & $7 \%$ \\
\hline \multirow[t]{2}{*}{ Mean } & 1.94 & 1.93 & 2.42 & 2.11 & 1.44 & 1.94 & 1.79 \\
\hline & & bcd & acdef & abdf & abcef & bdf & bcde \\
\hline SD & 1.32 & 1.40 & 1.32 & 1.41 & 1.19 & 1.37 & 0.97 \\
\hline
\end{tabular}

Letters in the table signify that the data within a particular country's cell was statistically significant at the 2-tailed 5\% level of significance (e.g. if the US had bcdef it would infer that the data was statistically significantly different to the other 5 countries).

Table 11. Concerns about infection.

\begin{tabular}{ccccccccc}
\hline & Total & US a & Germany b & Brazil c & China d & Russia e & India f \\
\hline BASE: total respondents & 3109 & 519 & 540 & 500 & 500 & 541 & 509 \\
Passing a cough/cold/flu on to others & $18 \%$ & $20 \%$ bcdf & $15 \%$ adf & $14 \%$ ad & $32 \%$ abcef & $16 \%$ df & $11 \%$ abde \\
Going to/performing at work & $18 \%$ & $18 \%$ & $18 \%$ c & $13 \%$ bdef & $22 \%$ c & $18 \%$ c & $20 \%$ c \\
Symptoms could develop into something worse & $16 \%$ & $23 \%$ bcdf & $21 \%$ acdf & $15 \%$ bef & $12 \%$ abef & $23 \%$ cdf & $5 \%$ abcde \\
Being able to sleep or rest at night & $12 \%$ & $16 \%$ cde & $17 \%$ cdef & $9 \%$ ab & $11 \%$ abe & $7 \%$ abdf & $12 \%$ be \\
Preparing meals and other household chores & $10 \%$ & $3 \%$ cdef & $4 \%$ cef & $13 \%$ abdf & $6 \%$ acef & $10 \%$ abdf & $22 \%$ abcde \\
\hline
\end{tabular}

Letters in the table signify that the data within a particular country's cell was statistically significant at the 2-tailed $5 \%$ level of significance (e.g. if the US had bcdef it would infer that the data was statistically significantly different to the other 5 countries).

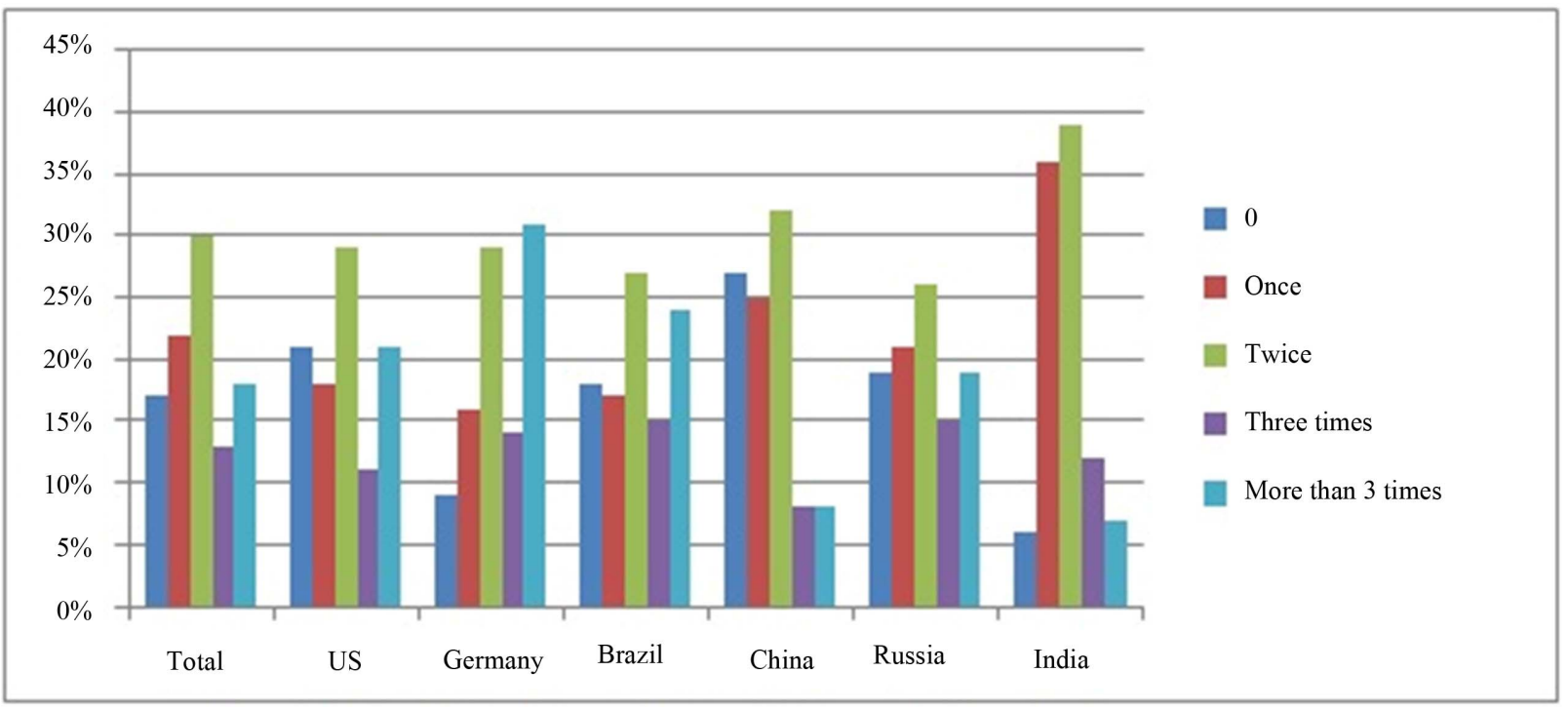

Figure 6. Sleep disturbance number of times a night wake up due to CCE symptoms. 
Table 12. Mood when experiencing URTI.

\begin{tabular}{ccccccccc}
\hline & Total & US a & Germany b & Brazil c & China d & Russia e & India f \\
\hline BASE: total respondents & 3109 & 519 & 540 & 500 & 500 & 541 & 509 \\
I feel down/unhappy /tired & $24 \%$ & $28 \%$ bcdf & $38 \%$ acdef & $7 \%$ abdef & $20 \%$ abc & $25 \%$ bc & $21 \%$ abc \\
I feel annoyed and irritable & $23 \%$ & $23 \%$ cdef & $21 \%$ cdef & $34 \%$ abde & $15 \%$ abcf & $16 \%$ abcf & $29 \%$ abde \\
I feel okay—it is just a cough/cold/flu & $16 \%$ & $21 \%$ bf & $9 \%$ acde & $18 \%$ bf & $21 \%$ bf & $17 \%$ bf & $8 \%$ acde \\
I feel let down by my body & $12 \%$ & $6 \%$ cef & $9 \%$ ce & $22 \%$ abdf & $7 \%$ cef & $19 \%$ abdf & $12 \%$ acde \\
I feel embarrassed by symptoms & $11 \%$ & $1 \%$ cdef & $2 \%$ def & $3 \%$ adef & $29 \%$ abcef & $9 \%$ abcdf & $21 \%$ abcde \\
\hline
\end{tabular}

Letters in the table signify that the data within a particular country's cell was statistically significant at the 2-tailed 5\% level of significance (e.g. if the US had bcdef it would infer that the data was statistically significantly different to the other 5 countries).

Respiratory illness was reported by many (60\% and $59 \%$ respectively) as inhibiting respondents from going shopping or outdoors in general. Those from the US, China and Russia were most impacted in this manner (69\%, 79\%, 72\%-shopping, and 61\%, 79\%, 73\%-outdoors, respectively). Working on hobbies, performing household chores and fitness regimes were less impacted in all countries (Data not shown).

\section{Discussion}

We believe this is the first survey to simultaneously report on the experience and impact of Common Colds and Flu in several countries across continents. The results of this study offer a reflective/retrospective snapshot of the effects of URTIs, the most frequently encountered infectious disease of humans [1-3] in a variety of social and cultural milieu. They complement and extend existing knowledge. Consistencies with earlier country-specific epidemiological reports $[5,8,9,11,12]$, were observed across the countries involved in this study, particularly with respect to reported incidence, duration and seasonality. In the other domains explored here, country specific differences were found and these offer some new insight into the impact of the condition(s) on patient's lives and their perspectives on the illness experience.

A survey of similar intent (assessment of the impact on life) and conducted in a single country (US) was recently reported at the 4th American Cough Conference [15]. This survey of 3300 US participants was designed to provide retrospective information about participant's cough/cold, impact of cough/cold on their lives, how they treat their cough/cold, views on unmet needs with current OTC medications and knowledge about the boilogy/pathophysiology of cough/cold. Overall the findings of this survey were broadly comparable (the questions were not disclosed so a precise comparison cannot be made) with those of the current study with respect to US respondents so the two approaches are complementary. Of particular interest is that Blaiss' group also identified a need for healthcare providers to educate patients on the non-prescription medications used for common cold. This product focused education would complement the basic physiology education recommended by the findings of our study.

The results of this survey indicate that while sufferers may be well informed about the symptoms/signs of common cold [1], they are not as well informed about how the infection is caught and transmitted. Only 22\% and $23 \%$ reported infections by work colleagues or spouse/ partner as the most likely route of infection. Interestingly there was an awareness (39\% of respondents) of the risk of infection in public places. However some of the ageold myths persist with exposure to cold environments being a significant cause reported overall (i.e. 34\% of respondents reporting sitting in a room with freezing temperatures), particularly in Brazil and China (44 and $55 \%$ of respondents respectively). This suggests that increased public education on respiratory virus transmission and avoidance (eg. use of hand washing and hand sanitisation sprays, gels etc.) may have a beneficial effect on the public health. As healthcare professionals (Pharmacists and Physicians) were reported most frequently as the source of information on Colds and Flu (73\% overall and up to $95 \%$ of respondents in India) this information may be most effectively delivered in the Pharmacy-the main source of non-prescription pharmacotherapy in some countries.

The social and economic effects of Common Cold/Flu described by Bramley et al. [7], and others were apparent from the responses to this survey. Overall, an average of up to 2.5 days per person annually was reported as lost to these infections. It is reasonable to suppose the finding that being able to carry on with a normal daily routine was most often reported as the reason for using medication by $32 \%$ of respondents overall is driven by the desire to avoid this loss.

Interestingly, the ability to get a good night's sleep when suffering from a Cold was reported by 33\% of respondents overall as a key reason to medicate, indicating that good quality sleep is considered a key aspect of re- 
covery and to being able to carry on with normal activities. This is consistent with the finding that they also reported waking at least twice per night when suffering from a Cold.

Consistent with these findings, when patients did treat they reported taking non-prescription medicines and multi-ingredient products were the most commonly reported (66\% of respondents). This choice is consistent with the belief that the Common Cold/Flu is “... a culturally accepted constellation of upper respiratory symptoms.” [16] that together induce the deleterious effects on mood and well-being. The second most used medications were for cough relief (58\% of respondents), reflecting perhaps its ability to disrupt social interactions and interfere with normal activities. This may also be driven by the well accepted association of cough and sleep disruption. Of interest here is the finding that $56 \%$ of respondents in the US reported using a multi-ingredient product (only Germany at 29\% was lower).

Several limitations of the study merit discussion. Firstly use of the colloquial term, "Cough Cold Flu” was used to be consistent with common language. With hindsight, this was unfortunate as on analysis it was not possible to distinguish respondents who had suffered a cough from conditions other than Colds and Flu. While any over-reporting is not judged to be fatal to the findings, future surveys should not include "cough" in the colloquial description of the condition(s). Secondly the study was entirely reflective and as such relied upon respondents accurately recalling their reactions and experiences over the past 12 months. While an "in-life" survey may have superior accuracy the consistency found in the previously reported epidemiological elements of the survey suggest that the reflective approach was valid. Thirdly, all respondents self-diagnosed in the sense that their recollections were of illnesses that they believed had been Common Cold or Flu. It was not ascertained whether they had had a physician diagnosis. In light of the fact that the symptom complex that characterises a Common Cold/Flu is so well recognised and generally treated without presentation to a physician, we judge this as unlikely to have had a significant effect on the findings.

As this survey was conducted in a wide variety of countries, local practices, legal constraints on the availability of non-prescription medicines and the perception of season may have had an effect on responses. In China and India for example traditional Chinese medicines and Ayurvedic remedies respectively are administered in non-traditional forms (teas, poultices, etc.), which may not be viewed as "medicine". The label "traditional medicines" was not included in the survey to facilitate comparability across geographical regions. Respondents made individual choices on which of the available re- sponses were most appropriate for any traditional remedies they might have used. The availability of non-prescription medicines varies significantly in the studied countries. Pharmacist-only, pharmacy-only, and unrestricted consumer choice represent the main modes of availability. This will have influenced some of the responses particularly in the US (mainly unrestricted consumer choice) and Germany (mainly Pharmacy-only). These have been highlighted where judged to be significant. India is a subtropical country where the concept of seasons is not strongly linked to autumn, winter, spring or summer. Responses from India related to season are most likely to have been focused on dry and rainy seasons.

This study provides a baseline of findings on sufferers' understanding of upper respiratory tract infections from a wide variety of social and cultural settings. It sheds light on the actual impact and experience of the condition(s) and indicates that these are similarly experienced in a variety of countries. It is intended that the survey will be repeated annually in an attempt to identify any trends in therapeutic choices and general understanding of the illness.

\section{Conclusions}

This study provides valuable insights into cultural differences in individual experiences across countries. While between-country impact and experience of URTIs differ in some respects, there are many shared aspects including:

- Incidence at approximately 2 adult URTIs annually with about a third lasting for 4 - 6 days;

- Some $70 \%$ of people rely upon/get help from healthcare providers;

- Multi-symptom (66\%), cough (58\%) and nasal congestion (38\%) were the most frequently reported OTC medicines used when suffering from an URTI;

- Sleep and its role in recovery is well accepted though not well understood, and good sleep quality is sought by many sufferers;

- URTIs affect the whole family unit in terms of overt infection and care required.

In more general terms the results of this study indicated that acute upper respiratory tract infections exert a significant deleterious effect on sufferers. Public health education, possibly best undertaken by Pharmacists has the potential to impact on the extent of virus transmission by ensuring that people know the true cause of the infection, how it is transmitted and how best to combat this. The several simultaneously occurring symptoms of URTIs encourage sufferers to seek multi-ingredient remedies to allow them to continue with their normal activities as the infection resolves naturally. 


\section{Acknowledgements}

The authors gratefully acknowledge the assistance of Tricia Gottlieb, Heather Huff, Liz Ming and Kevin Visco (employees of Procter \& Gamble) for valuable input into the redesign of the 2011/12 survey.

\section{REFERENCES}

[1] R. Eccles, "Is the Common Cold a Clinical Entity or a Cultural Concept?” Rhinology, Vol. 51, No. 1, 2013, pp. 3-8.

[2] D. Wat, "The Common Cold: A Review of the Literature,” European Journal of Internal Medicine, Vol. 15, No. 2, 2004, pp. 79-88. http://dx.doi.org/10.1016/j.ejim.2004.01.006

[3] T. Heikkinen and A. Jarvinen, "The Common Cold," Lancet, Vol. 361, No. 9351, 2003, pp. 51-59. http://dx.doi.org/10.1016/S0140-6736(03)12162-9

[4] F. G. Hayden and M. G. Ison, "Respiratory Viral Infections,” ACP Medicine, June 2006.

[5] Arruda, et al., "Frequency and Natural History of Rhinovirus Infections in Adults during Autumn,” Journal of Clinical Microbiology, Vol. 35, No. 11, 1997, pp. 28642868.

[6] R. Eccles, "Understanding the Symptoms of the Common Cold and Influenza," Lancet Infectious Disease, Vol. 5, No. 11, 2005, pp. 718-725. http://dx.doi.org/10.1016/S1473-3099(05)70270-X

[7] Bramley, et al., "Productivity Losses Related to the Common Cold," Journal of Occupational and Environmental Medicine, Vol. 44, No. 9, 2002, pp. 822-829. http://dx.doi.org/10.1097/00043764-200209000-00004

[8] Lidwell, et al., "The Epidemiology of the Common Cold.
IV. The Effect of Weather,” Journal of Hygiene (London), Vol. 63, No. 3, 1965, pp. 427-439. http://dx.doi.org/10.1017/S0022172400045319

[9] Gwaltney, et al., "Rhinovirus Infections in an Industrial Population. II Characteristics of Illness and Antibody Response,” Journal of the American Medical Association, Vol. 202, No. 6, 1967, pp. 158-164. http://dx.doi.org/10.1001/jama.1967.03130190100014

[10] A. S. Monto and B. M. Ullman, "Acute Respiratory Illness in an American Community," Journal of the American Medical Association, Vol. 227, No. 2, 1974, pp. 164 169. http://dx.doi.org/10.1001/jama.1974.03230150016004

[11] P. B. van Cauwenberge, "Epidemiology of Common Cold,” Rhinology, Vol. 23, No. 4, 1985, pp. 273-282.

[12] R. B. Turner, "Epidemiology, Pathogenesis, and Treatment of the Common Cold," Annals of Allergy Asthma and Immunology, Vol. 78, No. 6, 1997, pp. 531-539. http://dx.doi.org/10.1016/S1081-1206(10)63213-9

[13] A. S. Monto, "Epidemiology of Viral Respiratory Infections," American Journal of Medicine, Vol. 112, No. 6, 2002, pp. 4S-12S. http://dx.doi.org/10.1016/S0002-9343(01)01058-0

[14] R. Pawanker, G. W. Canonica, S. T. Holgate and R. F. Lockey, "WAO White Book on Allergy 2011-12: Executive Summary,” World Allergy Organization, 2011.

[15] M. S. Blaiss, "Attitudes of Consumers towards Health cOugh and cOld (ACHOO) Survey," Presented at the 4th American Cough Conference, 7 June 2013.

[16] W. Doyle and S. Cohen, "Etiology of the Common Cold: Modulating Factors,” In: R. Eccles and O, Webber, Eds., Common Cold, Birkhauser Verlag, Basel, 2009, pp. 149186. 